\title{
Magnusiomyces capitatus
}

National Cancer Institute

\section{Source}

National Cancer Institute. Magnusiomyces capitatus. NCI Thesaurus. Code C114263.

A yeast in the phylum Ascomycota. This species forms branched hyphae, and hyaline, ellipsoidal ascospores, and assimilates glucose, galactose, ethanol and glycerol. M. capitatus is an opportunistic pathogen and has been isolated from the human digestive and respiratory tracts as well as the blood of immunocompromised hosts. 